\title{
GESTÃO: SUA INFLUÊNCIA NO SUCESSO DAS AUTARQUIAS EM
}

\author{
ANGOLA \\ MANAGEMENT: ITS INFLUENCE ON THE SUCCESS OF AUTHORITIES IN
}

ANGOLA

\author{
Janísio C. Salomão ${ }^{1}$ \\ Patrícia Ortiz ${ }^{2}$
}

RESUMO: Com a aprovação do pacote legislativo que reúne as propostas de leis sobre as eleições autárquicas em Angola no dia 21 de Maio do ano de 2018, o país entrou numa velocidade cruzeiro para a realização das primeiras eleições autárquicas. Destarte, surgem uma série de indagações que necessitam ser minuciosamente refletidas e acauteladas para que a sua implementação ocorra sem sobressaltos. $O$ presente artigo visa analisar como a gestão pode influenciar no sucesso das autarquias em Angola. Ao longo do presente trabalho procura-se descrever a importância da gestão nas organizações, identificando de que forma ela pode influir no sucesso das autarquias, bem como analisa-se as melhores práticas para que através de autores e estudiosos na matéria, se consiga obter uma gestão de sucesso. Tratase de uma investigação empírica, do tipo descritiva. Procede-se a uma análise documental, pautando-se em fontes primárias e secundárias relevantes para à construção e embasamento do referido estudo. As questões relacionadas com o subdesenvolvimento, as assimetrias locais, a qualidade dos recursos humanos e a correcta gestão e/ou aplicação dos recursos constituem preocupações prementes para que as autarquias em Angola seja um sucesso. Nota-se que, as reflexões em torno das autarquias em Angola, têm tido como ponto nevrálgico o "gradualismo", seja ele funcional ou territorial, descartando-se da temática como a "gestão" que no entender dos autores, deve ser o cerne da questão pois, por mais que as autarquias possuam recursos sejam materiais, humanos ou financeiros, se não existir correcta gestão, as expectativas serão goradas.

Palavras-chave: Gestão; Autarquias; Autarquias em Angola; Gestão por Resultados.

ABSTRACT: With the approval of the legislative package that brings together the proposals for Laws on Municipal elections in Angola on May 21, 2018, the country entered a cruising speed for the first municipal elections, thus, a series of questions arise that, need to be carefully reflected and taken care of so that their implementation takes place smoothly. This article aims to analyze how management can influence the success of municipalities in Angola. Throughout this work, we seek to describe the importance of management in

${ }_{1}$ Mestre em Administração de Empresas, Instituto Superior Politécnico de Benguela. E-mail: janisio.salomao@ispbenguela.com. ORCID: https://orcid.org/0000-0003-3367-7117.

2 Mestre em Ciências da Educação, Instituto Superior Politécnico de Benguela. E-mail: patrícia.ortiz@ispbenguela.com. ORCID: https://orcid.org/0000-0002-8172-6801. 
organizations, we identify how it can influence the success of municipalities and we present the best practices so that, through authors and scholars in the field, successful management can be achieved. It is an empirical investigation, of the descriptive type. A documentary analysis is carried out, where they proceeded - recourse to relevant primary and secondary sources for the construction and foundation of the afore mentioned study. Issues related to underdevelopment, local asymmetries, the quality of human resources and the correct management and/or application of resources are pressing concerns for local authorities in Angola to be a success. It is noted that reflections on local authorities in Angola have had "gradualism" as a crucial point, whether functional or territorial, discarding the theme as "management" which, in the authors' view, should be the core of the question because, as much as the municipalities have resources, whether material, human or financial, if there is no correct management of them, expectations will be frustrated.

Keywords: Management; Municipalities; Municipalities in Angola; Management byResults.

Sumário: 1. Introdução; 2. A Gestão, Tipos e Características; 3. Tipos De Gestão; 4. Autarquias; 5. Autarquias em Angola; 6. Influência da Gestão nas Organizações; 7. Gestão de Sucesso como alcança-la nas Autarquias; 7.1 Características do Modelo GPR; 7.2 Modelos de Gestão por Resultados (GPR); 7.2.1 Orçamento Orientado Para Resultados; 7.2.2 Administração Por Objectivos (APO); 7.2.3 Contrato de Gestão 8. Prestação de Contas E Responsabilização (Accountability); 9. Considerações finais; 10. Referências.

\section{INTRODUÇÃO}

Com a aprovação do pacote legislativo que reúne as propostas de leis sobre as eleições Autárquicas em Angola no dia 21 de maio do ano de 2018, o país entrou numa velocidade cruzeiro para a realização das primeiras eleições aprazadas inicialmente para o ano de 2020, destarte, surgem uma série de indagações que, necessitam serem minuciosamente refletidas e acauteladas para que, a sua implementação ocorra sem sobressaltos.

Um estudo que visa refletir em torno da gestão, e como ela pode influenciar nas autarquias em Angola é de todo imperioso, pois o sucesso das autarquias está intrinsecamente relacionado com a forma que ela (autarquia) será gerida. Angola vive períodos sem precedentes relativamente a forma como foi gerido o erário público e concomitantemente a administração da máquina do estado nos últimos 16 anos.

As questões relacionadas com as assimetrias locais, a qualidade dos recursos humanos e a correcta gestão e/ou aplicação dos recursos constituem preocupações prementes 
para que a implementação das autarquias em Angola seja um sucesso.

Nota-se que, as reflexões mais recentes realizadas em torno das autarquias em Angola, tiveram e ainda possuem como ponto neurálgico o "gradualismo", seja ele funcional ou geográfico descartando-se temática como a "gestão" que ao entender dos auores deste trabalho, deve ser o cerne da questão pois que, por mais recursos que as autarquias venham a possuir, sejam eles materiais, humanos ou financeiros, se não existir correcta gestão dos mesmos, as expectativas criadas em torno das autarquias, acabaram por serem goradas.

O presente artigo tem como objectivo geral, analisar como a gestão pode influenciar no sucesso das autarquias em Angola. Os objectivos específicos consistiram:

1. Descrever os fundamentos teóricos relacionados com o tema;

2. Identificar de que forma a gestão pode influir nas organizações;

3. Analisar as melhores práticas para obter uma gestão de sucesso.

O estudo é não experimental, descritiva, do tipo exploratório-bibliográfico, procedeu-se a uma análise documental, com recursos a fontes primárias e secundárias relevantes para à construção e embasamento do referido estudo.

\section{A GESTÃO, TIPOS E CARACTERÍSTICAS}

Etimologicamente a palavra "gestão" provem do latim "gestione" refere-se à acção e ao efeito de gerir ou de administrar.

O termo gestão vem ganhando maior destaque ultimamente num mundo completamente adverso, marcado por crises cíclicas em que as organizações são rapidamente obrigadas a adaptar-se.

A gestão pode ser definida como acção ou efeito de gerir ou administrar, Luft (2001). Houaiss e Villar (2001) no dicionário de língua portuguesa Houaiss, definem gestão como o acto ou efeito de gerir, administrar, cuidar, executar e/ou praticar ou ainda exercer gerência sobre alguma coisa.

Confunde-se o termo gestão muitas das vezes com administração, mas existem autores que defendem que o termo gestão é mais abrangente e pode ser aplicado tanto para organização pública ou privada.

Dias (2002, p.2), afirma que, o "termo administração perdeu o seu status e cedeu 
parte de seu lugar para a gestão. Porém, quando se questiona as pessoas sobre o que é um termo e o outro, surgem as dificuldades da delimitação de ambos".

Por seu turno, Serra (2015, p.2), realça que "a gestão incorpora a administração e faz dela mais uma das funções necessárias para seu desempenho. A verdade é que a gestão se tornou um grande aglutinado de conhecimentos das mais variadas áreas do saber”.

Hoje, com as actuais mudanças organizacionais, fica mais claro que o desempenho de um gestor exige muito mais que administração. As funções do gestor são em princípio de fixar as metas a alcançar através do planeamento, analisar e conhecer os problemas a enfrentar, solucionar os problemas, organizar recursos financeiros, tecnológicos, ser um comunicador, um líder, ao dirigir e motivar as pessoas, tomar decisões precisas e avaliar, controlar o conjunto todo.

Rodriguez (2010) define a gestão sendo a forma em que os relacionamentos entre as pessoas acontecem, na busca de um objectivo comum.

Para Barbará (2008, p.14) define gestão como "um conjunto de actividades coordenadas para dirigir e controlar um grupo de pessoas e instalações com responsabilidade, autoridade e relações bem definidas".

Gestão pode também ser depreendida como o processo de conseguir obter resultados (bens ou serviços) com o esforço de outros. Pressupõem a existência de uma organização, isto é, varias pessoas que desenvolvem uma actividade em conjunto para melhor atingirem objectivos comuns.

De acordo os conceitos acima referenciados, se pode concluir que, a gestão é um conjunto de actividades interligadas e que deve permear todos os processos empresariais, interagindo no planeamento, implementação, medição, avaliação e monitoramento desses processos podendo evoluir ou simplesmente sucumbir. Consideramos que o termo gestão tornou-se bastante abrangente nos dias de hoje, tornando - se multifacetada e multidimensional.

A gestão tem entre suas funções: planejamento, organização, direção e controlo. No caso do planeamento é o processo de determinar antecipadamente o que deve ser feito e como fazê-lo. Organização por sua parte envolve a coordenação e combinação de recursos humanos, físicos e financeiros para que se produzam bens ou serviços que sejam 
simultaneamente procurados e que possam ser oferecidos a um preço que possa ser pago.

A direcção é a função administrativa que conduz e coordena as pessoas na execução das actividades planeadas e organizadas. O controlo é o processo de comparação do actual desempenho da organização, com valores e metas previamente defendidas, apontando as eventuais ações corretivas.

\section{TIPOS DE GESTÃO}

Gestão se desmembra em vários tipos, atendendo a critérios diferentes: podem ser: tradicional, moderna e contemporânea gestão financeira, gestão de recursos humanos, gestão de segurança privada, entre outros, (BARBARÁ, 2008).

Outros autores (SERRA, 2002 \& DIAS, 2015) coincidem nos seguintes tipos de gestão: gestão administrativa, gestão de recursos humanos, gestão de projectos, gestão do conhecimento, gestão ambiental, gestão social, gestão financeira, gestão autárquica etc.

A gestão em termos gerais, tem como características:

- $\quad$ Participação

- Capacitação;

- $\quad$ Envolvimento;

- Desenvolvimento.

\section{AUTARQUIAS}

A palavra autarquia é origem grega "autárkeia" que significa comandar a si mesmo. É o tipo de governo em que uma pessoa ou um grupo de pessoas concentram o poder sobre uma nação. Autarquia é quando o Estado tem total autonomia sobre si próprio, é autosuficiente.

Autarquia, é, pessoa jurídica de direito público de capacidade exclusivamente administrativa.

Amaral (2006, p.6), realça que autarquia é uma "pessoa jurídica de direito público, integrante da administração indireta, criada por lei para desempenhar funções que, despidas de carácter económico, sejam próprias e típicas do Estado", assim considerando como autarquia. 
Por fim, Figueiredo (2016, p.10) salienta que, autarquia é, "a pessoa jurídica de direito público, criada por lei, com capacidade de autoadministração, para o desempenho de serviço público descentralizado, mediante controlo administrativo exercido nos limites da lei".

Então é óbvio que a Autarquia é o serviço autónomo, criado por lei, jurídica, património e receita próprios, para executar actividades típicas da Administração Pública, para seu melhor funcionamento. As autarquias representam uma extensão da administração directa, realizando actividades do Estado.

Medauar (1999), afirma que as autarquias se caracterizam por possuírem personalidade jurídica própria, sendo assim, sujeitos de direitos e encargos, por si próprias. Caracterizam-se ainda por possuírem património e receita própria o que significa que os bens e receitas das autarquias não se confundem, em hipótese alguma com os bens e receitas da Administração directa a que se vinculam, sendo estas geridas pela própria autarquia.

De acordo a Constituição da República de Angola (CRA):

As autarquias locais são pessoas colectivas territoriais correspondentes ao conjunto de residentes em certas circunscrições do território nacional e que asseguram a prossecução de interesses específicos resultantes da vizinhança mediante órgãos próprios representativos das respectivas populações. (CRA, 2010, p. 82)

Pode-se depreender que o conceito de autarquia encerra em si a existência de um ente com personalidade jurídica, e que possui autonomia administrativa, financeira e patrimonial, com a finalidade de satisfazer as necessidades de uma determinada colectividade.

\section{AUTARQUIAS EM ANGOLA}

A implementação das autarquias em Angola é uma premissa constitucional, consagrado na CRA desde o ano de 2010 (MEDAUAR, 1999); apesar disto, a sua materialização nunca chegou a ocorrer. De referir que, a anterior CRA de 1992 já consagrava o princípio das autarquias locais no seu artigo $146 .^{\circ}$

A autonomia local compreende o direito e a capacidade efectiva das autarquias locais gerirem e regulamentarem, nos termos da Constituição e da lei, sob sua responsabilidade e 
no interesse das respectivas populações, os assuntos públicos locais, (Artigo n $^{\mathbf{0}} 214$, n. $^{\circ} 1$ CRA, 2010).

A organização e o funcionamento das Autarquias Locais, bem como a competência dos seus órgãos, são regulados por lei, de harmonia com o princípio da descentralização administrativa.

No artigo 218 da Constituição da República de Angola, estabelece á organização das Autarquias: Organizam-se tendo em conta as especificidades culturais, históricas e o grau de desenvolvimento, podem ser constituídas autarquias de nível supramunicipal.

A lei pode ainda estabelecer, de acordo com as condições específicas, outros escalões inframunicipais da organização territorial da Administração local autónoma.

Feijó (2001, p.66) realça que, apesar de um quadro constitucional que respeite na sua organização a existência de instituições locais e autónomas assentes nos princípios da “descentralização e da autonomia”, o poder autónomo dos entes de governo subnacional não está institucionalizado na prática.

Volvidos 18 anos, começa -se a debater o assunto sobre as autarquias em Angola com acuidade, e destarte, são lançadas as sementes/bases para a sua efectivação.

No pretérito dia 21 de maio do ano de 2018, o Conselho de Ministros da República de Angola, apreciou o pacote Legislativo sobre as Autarquias Locais, e o mesmo, foi igualmente submetido a consulta pública no período de 01 de junho a 31 de julho, um período de duração de 2 (dois) meses.

A realização das primeiras eleições autárquicas encontrava-se aprazadas para o ano de 2022, ficando apenas por saber se será realizada em todo território nacional, ou em alguns municípios previamente identificados, tendo em atenção o princípio do gradualismo (CRA, 2010, artigo $\left.242 .^{\circ}\right)$.

Béu realça que,

A materialização das autarquias em Angola, é um imperativo incondicional para que haja descentralização do poder e maior fluidez dos serviços. Esta descentralização trará consigo muitas melhorias não só no que tange ao funcionamento dos serviços prestados pelas instituições públicas mas permitirá também a participação da população nas questões económicas e políticas, haverá uma melhor distribuição dos bens e serviços, melhor liberdade de expressão, entre outros (BÉU, 2017, p. 358) 
Rocha destaca:

Angola é possivelmente o País Africano mais centralizado - quer olhemos para o sistema político, administrativo ou financeiro. É excepcional a centralização financeira, se verificarmos como a receita fiscal angariada localmente é recolhida pelo Ministério das Finanças e depositada na Conta Único do Tesouro (CUT) - tal como é excepcional a maneira como o investimento público é dirigido da capital do país. Uma das consequências, bastante provável, mas não inevitável, é a formidável concentração em Luanda das despesas públicas correntes e do investimento público. (ROCHA, 2010, p. 24)

A implementação das autarquias em Angola, é sem sombra de dúvidas um dos ingredientes necessários imprescindíveis para a melhoria da condição de vida dos cidadãos, pois melhor do ninguém apenas eles saberão o que os aflige, quais as suas principais necessidades, no entanto, julgamos também por outro lado, torna -se imperioso que os principais gestores (autarcas) possuam conhecimentos necessários para garantir o alcance dos objectivos preconizados, pois nem sempre uma descentralização traduz -se na melhoria de condições de vida dos cidadãos.

No entanto, Lisboa defende:

A descentralização não é um objectivo em si mesmo, e a questão não se limita em ter autarquias apenas por ter, mas, sim, como desenhá-la, como conformá-la, e, em última instância, que modelo de descentralização adoptar. Porém, no seu entender, o sucesso da descentralização em Angola dependerá em grande medida do modo como for desenhado (LISBOA, 2018, p. 18)

\section{INFLUÊNCIA DA GESTÃ̃ NAS ORGANIZAÇÕES}

Amaral (2006, p.481) afirma que as autarquias locais são pessoas destintas do Estado. "Elas não fazem parte do Estado, não são o Estado, não pertencem ao Estado. São "entidades independentes" e completamente destintas do Estado embora possam por ele ser fiscalizadas, controladas ou subsidiadas".

Tomamos como âncora a tese apresentada por Amaral para afirmar que a autarquia é uma "organização": "A organização é um sistema planejado de esforço cooperativo no qual cada participante tem um papel definido a desempenhar e deveres e tarefas a executar". (CURY, 2000, p. 116). 
A organização é um artefacto que pode ser abordado como um conjunto articulado de pessoas, métodos e recursos materiais, projetado para um dado fim e balizado por um conjunto de imperativos determinantes (crenças, valores, culturas etc.) (MEIRELES, 2003, p. 46).

Restrepo e Ângulo (1992) enfatizam que as organizações são unidades particulares formadas para atingir fins específicos, dirigidos por um poder que estabelece uma forma de autoridade que determina o status e o papel dos membros da organização.

O conceito de organização pode aqui ser encarado na forma como se dispõe um sistema para atingir os resultados pretendidos, podendo variar de acordo a finalidade que se propõe.

Pois tal conforme destaca Etzioni (1989), existem muitas organizações que, simultaneamente e legitimamente, têm dois ou mais objectivos, isto é, possuem finalidades múltiplas; deixando claro que a organização deve ser vista como uma unidade social que procura atingir objectivos específicos, sendo estruturada para tal. Sob uma perspectiva estruturalista, as organizações são intencionalmente construídas e reconstruídas.

Cury (2000) classifica as Organizações segundo três critérios: Flexibilidade, Complexidade e Evolução Histórica.

A autarquia é sem dúvida uma organização cuja finalidade de reveste na satisfação das necessidades da colectividade, e para tal, necessita de reunir um conjunto de recursos e, estejam acima de tudo comprometidos com o alcance de objectivos, destarte, deve pautar o seu funcionamento em normas, princípios e regras de gestão.

Falar de gestão pressupõe falar de um gestor que normalmente é o responsável pelo sucesso ou insucesso da organização.

De acordo Drucker (2007), muito dos insucessos das organizações são frutos de uma gestão ineficaz, sendo intrinsecamente relacionadas com o líder.

A forma como é gerida uma organização influenciará sem sombra de dúvida no sucesso da respectiva organização. Hoje em dia um dos grandes desafios é gerir uma equipa que consiga alcançar os resultados preconizados. Para tal o gestor necessita de ser habilidoso para conseguir fazer a correcta dosagem dos recursos colocadas à sua disposição.

\section{GESTÃO DE SUCESSO COMO ALCANÇÁ-LA NAS AUTARQUIAS}


A criação e implementação de autarquias locais e a realização de eleições autárquicas é um processo complexo e sensível em qualquer país, ainda mais em Angola, dada a realidade política, histórica, mas também a situação económica e financeira que atravessa actualmente.

Não existe uma fórmula mágica em gestão que conduza ao sucesso. A verdade é que todas as organizações almejam alcançar o sucesso, mas poucas conseguem. A gestão de sucesso requer a combinação de uma série de factores para sua efetivação.

Uma gestão da administração local não exige apenas uma outra racionalidade económica (CANOTILHO, 2000). Ela passa pela mudança de postura na administração autárquica, tal como na administração central, visando um serviço público de qualidade com eficiência, eficácia, economicidade e flexibilidade, sendo fundamental a inovação através da criação de novas condições de interação entre a tecnologia e as dimensões sociais, económicas e culturais, tendendo a uma desburocratização dos serviços e aproximação aos cidadãos.

É ainda necessária, uma restruturação que melhor responde à satisfação das necessidades dos munícipes e ao nível operacional ou técnico, é preciso novas técnicas de gestão dos recursos, sendo que no tocante aos Recursos Humanos, há que se olhar para os problemas relativos à motivação, avaliação, remuneração e produtividade (BILHIM, 2004).

Igualmente o sucesso das Autarquias em Angola depende de uma série de condimentos que devem necessariamente serem colocados em cima da mesa ou ponderados, na altura da sua implementação, de entre os quais destacaram-se os seguintes:

Qualidade e Gestão dos Recursos Humanos (1) colocados à disposição do Gestor. Os recursos humanos são vistos hodiernamente como um dos maiores recursos que as organizações possuem, pois são responsáveis pela materialização dos propósitos definidos pela organização. O sucesso das autarquias em Angola dependerá de certa forma da qualidade recursos humanos afectos/disponíveis nas autarquias; de outro modo, uma correcta gestão dos recursos humanos pode igualmente, fazer toda a diferença no sucesso e insucesso das autarquias.

De acordo Ivancevich (2007) "cada vez mais as organizações consideram a gestão de Recursos Humanos como um "centro de lucros" e não apenas como um "centro de 
custos".

Num mundo em constantes mutações em que a exigência pela prestação de um serviço de qualidade torna-se imperioso, exige indubitavelmente recursos humanos a altura das exigências.

Outrossim, é importante que o Gestor (autarca) saiba manejar correctamente os recursos humanos colocados à sua mercê, promovendo um bom ambiente organizacional, à cultura da meritocracia, invista na capacitação permanente dos recursos humanos, permita o feedback, de modos que os colaboradores directos efectuem críticas construtivas quando os erros forem cometidos pelas equipes.

Introdução de métodos de Avaliação de desempenho (2). Nesse sentido, Drucker (1986) já dizia que “não se pode gerir o que não se consegue medir”. Já parou para perguntar quanto produz um funcionário/colaborador dentro da tua organização? A avaliação de desempenho é uma das ferramentas preponderantes que nos ajuda a fornecer esta informação, é sem dúvida essencial na gestão de pessoas.

\footnotetext{
A tarefa de gerir pessoas não é tão linear quanto parece, pois é importante analisar profundamente o contexto organizacional, nomeadamente no que diz respeito as relações, comportamentos e competências técnicas dos profissionais ao dispor da entidade. Esta análise deve ser realizada anualmente, de forma a ajustar as características profissionais dos trabalhadores. (PEREIRA, 2010, p. 22)
}

Avaliação de desempenho, tornou -se uma ferramenta que auxilia o gestor na tomada de decisões sobre medidas relativas aos colaboradores, nomeadamente: o desempenho dos funcionários relativamente as funções acometidas, avaliar se os objectivos definidos pela organização foram ou não alcançados, identificar o grau de contribuição de cada colaborador na organização, quais as razões que concorreram para tal facto, se o funcionário necessita ou não de formação, promoção ou desenvolvimento profissional ou se a remuneração encontrase desajustada, promover o autodesenvolvimento dos colaboradores. É uma ferramenta que permite trazer alguma justiça social, na forma como o autarca poderá avaliar os seus colaboradores directos.

Planejamento Estratégico (3). Trata-se de todo o processo de criação e execução de uma estratégia para alcançar objectivos dentro da organização. Desde a definição das metas, 
até às tomadas de decisão, mobilizações e efetivas ações para alcançar o que se propôs com foco no sucesso da autarquia.

O planeamento entra com a metodologia (os meios), enquanto a estratégia aparece com a parte criativa, de análise e decisão.

Este plano pode ser feito anualmente; ou com uma proposta mais a longo prazo, como de três a cinco anos; ou até mesmo mensalmente. Tudo irá depender do que quer alcançar com a sua organização no momento.

Afinal, se o gestor sente que está ficando para trás, que a concorrência esteja chegando perto ou tem alguma meta específica, seja para alavancar os objectivos ou se diferenciar com uma nova ação, não tem que se deixar para depois

Assim que entender o que é planeamento estratégico, poderá (aliás, deverá) utilizálo imediatamente na hora em que mais precisar.

Para cumprimentar com as metas traçadas poderá ter em conta as etapas do planeamento estratégico:

- $\quad$ Avaliação de ambiente

- $\quad$ Elaboração da estratégia

- Desenvolvimento do plano de execução

- $\quad$ Envolvimento das pessoas

Assim sendo ao finalizar essas etapas será capaz de ter as condições para a implementação da Gestão por Resultados (GpR).

Por fim, Implementação de uma Gestão por Resultados (GpR) (4). O termo Gestão para Resultados (GpR) é uma variante da teoria da Administração por Objectivos (ApO) implementada por Peter Drucker. A GpR eclodiu no sector privado, mas acabou por alargar-se também para o sector público. Contribuiu para reflexões de assuntos relacionados com a necessidade de melhoria da qualidade, eficiência e eficácia dos serviços públicos bem como o desempenho dos servidores e organizações públicas.

Segundo Gomes (2009, p.17), “o modelo de Gestão para Resultados é uma das principais recomendações da Nova Gestão Pública. Ele seria focado na efectividade da política pública, na flexibilização das normas e procedimentos, e na melhoria da eficiência e accountability do Estado." 
A GpR é um modelo vantajoso pois permite que as organizações adoptem um modelo que traz maior flexibilidade nos processos, melhor relacionamento e motivação entre os colaboradores de uma organização.

É uma forma de administrar, em que todos os profissionais/colaboradores da organização têm como foco principal os resultados.

\subsection{CARACTERÍSTICAS DO MODELO GPR}

A aplicação desse conceito traz algumas características essenciais de entre as quais destacamos as seguintes:

A responsabilidade colectiva (1): Todos os colaboradores são responsáveis pelos resultados alcançados pela autarquia, independente das diferentes funções que cada um assume, incluindo as oportunidades desperdiçadas ou mesmo perdas. Existe uma envolvência colectiva na definição dos objectivos, e igualmente os esforços desprendidos são reconhecidos.

Integração de todas as áreas da organização (2): As diversas unidades de negócios deverão contribuir com cada uma de suas tarefas específicas, mas deverão trabalhar juntas, de maneira integrada e voltadas para resultados em comum. Assim sendo, as relações entre líderes e liderados são mais próximas, com uma troca de informações mais fluída.

Resultados - e não processos (3): Apesar de existirem diretrizes a cumprir, não existe rigidez no seu cumprimento de tais acções. $\mathrm{O}$ foco continua a ser os resultados preconizados e não os processos ou procedimentos utilizados pelas autarquias.

Tal conforme destacou Garces e Silveira (2002, p. 56), entende-se por resultado "a solução de um problema ou o atendimento de demanda da sociedade - mensurados pela evolução de indicadores no período de execução do programa, possibilitando, assim, avaliação objectiva da atuação do governo".

\subsection{MODELOS DE GESTÃO POR RESULTADOS (GPR)}

Actualmente são variadíssimos os modelos de GpR existentes. Dos modelos apresentados por Paludo (2013) destacaremos apenas 3 (três) modelos de gestão por resultados:

1. Sistema Orçamentário orientado para resultados; 
2. Administração por objectivos;

3. Contrato de gestão.

4. Prestação de Contas e Responsabilização (accountability)

\subsubsection{Orçamento Orientado Para Resultados}

O orçamento por resultados abandona as práticas incrementais em prol de uma visão voltada para a eficiência na alocação de recursos, transformando o orçamento num instrumento vigoroso, capaz de promover a sinergia e obter melhores resultados organizacionais (PALUDO, 2013).

Faria (2010) realça que o núcleo conceitual do Orçamento por Resultados se assenta sobre a ideia básica de que a informação sobre o desempenho de órgãos, agências e programas deve ser desenvolvida, integrada ao processo orçamentário e - principalmente utilizada como elemento relevante do processo de tomada de decisão.

Paludo (2013, p. 608) afirma que o orçamento por resultados reforça a confiança das instituições estabelecidas e melhora a aceitação dos governos, contribui tanto para o desenvolvimento socioeconómico da nação, tanto para a eficiência, eficácia e efectividade da gestão pública.

\subsubsection{Administração Por Objectivos (APO)}

Conforme Drucker (1986), na administração por objectivos (APO) cada membro da organização contribui com algo diferente, mas todos devem contribuir para um objectivo comum. Seus esforços devem puxar todos na mesma direção, e suas contribuições devem ajustar-se conjuntamente para produzir um todo, sem lacunas, sem atritos e sem duplicação desnecessária de esforços.

Neste modelo o desempenho do gestor é avaliado em função da sua contribuição no alcance dos resultados e sucesso da organização previamente definidos.

O gestor (autarca) deve entender quais as principais demandas dos liderados e quais são as metas esperadas em termos de desempenho, e os órgãos que o superintendem devem saber avaliar e exigir. Se esses requisitos não forem cumpridos significa que os gestores são mal direcionados e seus esforços são desperdiçados (DRUCKER, 1986). 
A administração por objectivos (APO) é um sistema de administração que vincula objectivos e metas organizacionais com o desempenho individual, em todos os sectores. $\mathrm{O}$ planeamento organizacional precede a definição dos objectivos e da estratégia, com a finalidade de incorporar a racionalidade na actuação administrativa (PALUDO, 2013).

Drucker (1986) ainda explica que uma organização deve realizar esforços para tornar sua gestão focada em objectivos. O autor explica que uma organização, por sua natureza, contém quatro factores que podem desviá-la dos objectivos:

- $\quad$ A especialização do trabalho da maioria dos gestores;

- A estrutura hierárquica; as diferenças na visão de trabalho e a consequente;

- $\quad$ Isolação dos diversos níveis da organização; e finalmente;

- $\quad$ A estrutura de remuneração dos gestores.

\subsubsection{Contrato De Gestão}

O Contrato de Gestão teve origem na segunda metade da década de 60 na França. Na altura surgem dois modelos de gestão: Contrato de Plano, com aplicação a órgãos da administração directa e o Contrato de Serviços aplicado a empresas públicas.

No ano de 1979 este instrumento ganha um novo impulso na Inglaterra, através da introdução de uma nova experiência de gestão. Os ingleses estavam em busca de uma transformação que fosse mais durável nas formas de gestão da Administração Pública.

Modesto (2010, p.6) denominou o contrato de gestão, entre o Poder Executivo e órgãos da administração como "um contrato de autonomia", ou seja, um acordo de gestão. Como norma legal especial, ele defende que: "a lei pode tratar diferentemente entidades e órgãos que assinem Contratos de Gestão”.

Os contratos de gestão surgem então como um instrumento que permite maior controle administrativo dos gestores, uma vez que, os objectivos e metas são previamente fixadas, tornando -se assim, um importante elemento no monitoramento e comprometimento dos agentes e dirigentes, além de traduzir - se numa efectiva ampliação da competência pública.

Paludo (2013) explica que o "contrato de gestão se aproxima da administração por objectivos. Nele as instituições firmam compromisso para o alcance de objetivos e recebem 
um orçamento global para custear a realização das actividades”.

É um dos mecanismos para permitir melhor controlo dos recursos alocados em função dos objectivos definidos, fazendo com que os desvios orçamentais se verifiquem em proporções significativas.

\section{PRESTAÇÃO DE CONTAS E RESPONSABILIZAÇÃO (ACCOUNTABILITY)}

O termo accountability é de origem Anglo-saxónica, e tem sido tratado na literatura de forma abrangente e variada. Não existe em português um termo único para expressar o termo, ela necessita de trabalhar de forma composta.

A ausência de prestação de contas ou informações da parte de gestores públicos ou governantes fez com que o termo ganhasse maior notoriedade nos últimos tempos.

Schedler (1999, p. 4) afirma que accountability como forma de cobrar respostas dos governantes ocorre exatamente porque existem de ciências nas informações que são passadas ao público, "Nesse caso, a accountability (como answerability) pretende criar mais transparência em relação ao exercício do poder”.

De acordo Pinho e Sacramento (2008, p.2), accountability "encerra a responsabilidade, a obrigação e a responsabilização de quem ocupa um cargo em prestar contas segundo os parâmetros da lei, estando envolvida a possibilidade de ónus, o que seria a pena para o não cumprimento desta directiva".

De uma forma mais abrangente a accountability se realiza, quando o cidadão exerce o seu poder de soberania ao eleger os seus governantes ou representantes durante o processo eleitoral através do voto. Igualmente, ela também ocorre quando se realiza no dia-a-dia a actuação dos agentes e das organizações públicas.

O’Donnell (1998), apresenta dois planos da divisão clássica da accountability:

- Accountability vertical - em que a sociedade exerce o seu poder de premiar ou punir seus governantes e representantes mediante a sua manutenção ou retirada do poder por intermédio do voto directo em eleições livres entre outros mecanismos de pressão política;

- $\quad$ Accountability Horizontal - definida como aquela que se efetiva mediante a 
mútua fiscalização entre os poderes (checks and balances), por meio de órgãos governamentais que controlam a actividade pública e, principalmente, pela existência de agências estatais com poder, vontade e capacitação para supervisionar, avaliar e punir, se for o caso, agentes ou agências governamentais.

Por seu turno Miguel (2005, p. 23), alega que a "accountability diz respeito à capacidade que os cidadãos têm de impor sanções aos governantes, reconduzindo ao cargo aqueles que exerceram bem os seus mandatos e destituindo aqueles que não o fizeram”.

A cultura da prestação de contas torna -se assim um factor sine qua non para a salvaguarda dos direitos dos cidadãos, tal conforme o poder é cedido aos gestores para que em nome do povo dirijam com transparência, isenção os destinos das autarquias, os mesmos têm a responsabilidade de prestar contas a quem os elegeu. Este exercício é, sem sobra de dúvida o garante da manutenção dos cargos dos servidores públicos.

\section{CONSIDERAÇÕES FINAIS}

Dos conceitos relacionados com gestão, podemos aferir que o termo gestão e administração são muitas vezes confundidos, e ao longo do artigo constou-se que, o conceito de gestão é mais abrangente, pois vem ganhando maior destaque ultimamente, num mundo em que as organizações encontram-se numa competitividade frenética; o conceito de gestão, reúne um conjunto de técnicas indispensáveis e ademais, incorpora dentro de si o termo administração e faz dela, uma das funções necessárias para o seu desempenho.

A gestão tornou - se um aglutinado de conhecimento das mais variadas áreas, o que torna ela uma ciência multifacetada e multidimensional. A gestão pode influir nas organizações; o sucesso da autarquia dependerá imprescindivelmente, da forma como será gerida pelo autarca, pois, a correcta conjugação dos recursos será um factor preponderante; actualmente os recursos humanos são encarados como um dos principais activos mais relevantes das organizações e saber gerir uma equipe constitui um dos principais desafios da gestão moderna. A gestão tornou-se nos dias de hoje uma ferramenta imprescindível para as organizações.

O estudo deixou claro que as autarquias podem alcançar uma gestão de sucesso, no entanto, o sucesso depende de uma série de conjugação de factores relevantes relacionados 
com a gestão, que necessitam de serem acauteladas de entre eles: (1) a gestão e a qualidade dos recursos humanos (2) o autarca deve introduzir métodos que permitam a avaliação de desempenho do pessoal, para garantir a mensuração da produtividade do colaborador, as debilidades, necessidades de formação/capacitação, promoção ou auto-desenvolvimento profissional do colaborador; (3) identificou -se que a implementação da Gestão por Resultados (GpR) melhora a qualidade, eficiência e eficácia dos serviços bem como, o desempenho dos servidores públicos, por ser uma ferramenta que tem como foco principal o "resultado" e traz consigo uma maior flexibilidade nos processos, melhor relacionamento e motivação entre os colaboradores de uma organização.

\section{REFERÊNCIAS}

AMARAL, D. F. Curso de Direito Administrativo. 3. ed., 2a. Reimp. Lisboa: Edições Almedina. 2006.

ASSAMBLEA Nacional. Constituição da República de Angola. 2010. Disponível em https://www.wipo.int/edocs/lexdocs/laws/pt/ao/ao001pt.pdf

BARBARÁ, S. Gestão por processos: fundamentos, técnicas e modelos de implementação. Rio de Janeiro: Qualitymark, 2008.

BEU, C. C. A implementação das Autarquias em Angola como alavanca para a resolução de problemas locais. Revista da Academia Brasileira de Direito Constitucional. 2017. Disponível em: http://www.abdconstojs.com.br/index.php/revista/index. Acesso em: 20 ago. 2021.

BILHIM, J. A Governação nas Autarquias Locais. (S. P. De Inovação, Ed.). Colecção Inovação e Governação nas Autarquias 2004. Porto: Principia, Publicações Universitárias e Científicas. Disponível em: https://www.temposdegestao.com/conceito-de/conceito-degestao. Acesso em: 20 ago. 2021.

CANOTILHO, J. J. G. Paradigmas de Estado e paradigmas de administração Pública. In: I. N. de Administração \& F. Gulbenkian (Eds.). Moderna gestão pública: dos meios aos resultados - Acta Geral do 2o Encontro INA Lisboa, 30.31 março: Instituto Nacional de Administração 2000 (Org.).

CURY, A. Organização e métodos: uma visão holística. - 7. ed. rev. e ampl. São Paulo: Atlas, 2000.

DIAS, E. P. Conceitos de Gestão e Administração: Uma visão Crítica. Revista Eletrônica de Administração - Facef, v.01, ed.01, p. 2, 2002 
DRUCKER, P. Management: tasks, responsibilities and practices. 1986 New York: Truman Talley Books.

DRUCKER, P. O gerente eficaz em açcão: uma agenda para fazer as coisas certas acontecerem. Rio de Janeiro: LTC, 2007.

ETZIONI, A. Organizações modernas. 8 ed. São Paulo: Pioneira, 1989.

FARIA, R. O. Novas Abordagens do Orçamento Público. 2010. Monografia. Prêmio SOF de Monografias - Secretaria de Orçamento Federal

FEIJÓ, C. Problemas Actuais de Direito Público Angolano. Contributos para a sua compreensão. Principia, 2001.

FIGUEIREDO. D, A, et. Al. Curso de Direito Administrativo. v. I, 4. ed. 2016.

GARCÊS, A; Silveira, P. Gestão pública orientada para resultados no Brasil. Revista Do Serviço Público, v. 53, n. 4, p. 53-77, 2002.

GOMES, E. G. M. Gestão por Resultados e eficiência na Administração Pública: uma análise à luz da experiência de Minas Gerais. Tese de Doutorado em Administração Pública e Governo. 2009.

HOUAISS A; VILLAR, S. M. Dicionário da língua Portuguesa. Rio de Janeiro, Objectiva, 2001

IVANCEVICH, J M. Gestão de Recursos Humanos. Ed. Mc Graw Hill, 2007.

LISBOA, E. O. Sucesso da descentralização em angola depende do desenho. 2018. Jornal o país. Disponível em: https://opais.co.ao/index.php/2018/05/10/o-sucesso-dadescentralizacao-em-angola-depende-do-desenho/. Acesso em: 20 ago. 2021.

LUFT, C. P. Minidicionário. 20. ed. São Paulo: Ática, 2001.

MEDAUAR, O. Direito Administrativo Moderno. 3. ed. São Paulo: Revista dos Tribunais, 1999.

MEIRELES, M. Teorias da administração: clássicas e modernas. São Paulo: Futura, 2003.

MIGUEL, L. F. Impasses da Accountability: Dilemas e Alternativas da Representação Política. Revista de Sociologia e Politica, 2005. Disponível em: https://www.scielo.br/j/rsocp/a/jYssQtnjyqSTTbFQwnQw8YR/abstract/?lang=pt. Acesso em: 19 ago. 2021.

MODESTO, P. Contrato de Gestão no Interior da Organização Administrativa como Contrato de Autonomia. Revista Eletrônica sobre a Reforma do Estado. Novembro de 2010. 
O’DONNELL, Guillermo. Accountability horizontal e novas poliorquias. Revista Lua Nova, v. $44, \quad$ p. 27-54, 1998. Disponível em: https://www.scielo.br/j/ln/a/jbXvTQR88QggqcdWW6vXP8j/abstract/?lang=pt. Acesso em: 19 ago. 2021.

PALUDO, Augustinho. Administração Pública. 3. ed. Rio de Janeiro: Elsevier, 2013.

PEREIRA, A. C. Gestão de Potencial Humano numa Instituição Autárquica. 2010. Disponível em: https://core.ac.uk/download/pdf/19129227.pdf. Acesso em: 19 ago. 2021.

PINHO, J.A. G; SACRAMENTO, A. R. S. Accountability. Anais do Encontro de Administração Pública e Governança da Associação Nacional de Pós-Graduação e Pesquisa em Administração. Salvador/BA, Brasil, 2008.

RESTREPO, M. J; ANGULO, J. R. Intervir en la organización. Bogotá: ignificantes de Papel Ediciones, 1992.

ROCHA, M. J. A. Desigualdades e Assimetrias Regionais em Angola - os factores de competitividade territorial. Universidade Católica de Angola - Centro de Estudos e Investigação Científica, Luanda, 2010.

RODRIGUEZ, V.R. M. Gestão empresarial: organizações que aprendem. Rio de Janeiro: Qualitymark, 2010.

SCHEDLER, A. Conceptualizing Accountability. 1999. In: A. Schedler, L. Diamond, \& M. Plattner, (Ed.) Self-Restraining State: Power and Accountability in New Democracies. Boulder: Lynne Rienner Publishers, 1999.

SERRA, R. F. Gestão Estratégica Conceitos e Prática. Lidel, 2002. Disponível em: https://www.bertrand.pt/livro/gestao-estrategica-fernando-ribeiro-serra/4939910. Acesso em: 19 ago. 2021/. 